\title{
EHMTI-0154. Brainstem mechanisms of trigeminal nociception: an fMRI study at $3 \mathrm{~T}$
}

\author{
L Schulte ${ }^{*}$, C Sprenger, A May \\ From 4th European Headache and Migraine Trust International Congress: EHMTIC 2014 \\ Copenhagen, Denmark. 18-21 September 2014
}

\section{Introduction}

The brainstem is the major site of trigeminal pain processing and modulation and plays a key role in the pathophysiology of various headache disorders. However, comprehensive human imaging studies on function and activity of brainstem areas following trigeminal nociceptive stimulation are scarce.

\section{Aim}

To develope a viable protocol for brainstem fMRI of standardized trigeminal nociceptive stimulation.

\section{Methods}

21 healthy participants (16 female) were scanned on a $3 \mathrm{~T}$ scanner with a standardized trigeminal nociceptive stimulation protocol for event-related fMRI using a specifically designed sequence for high resolution brainstem echo planar imaging as well as a brainstem specific noise correction technique and brainstem template.

\section{Results}

We observed significant BOLD responses in areas typically involved in trigeminal nociceptive processing such as the spinal trigeminal nuclei (sTN), thalamus, SII, insular cortex and cerebellum as well as in a pain modulating network including the dorsal raphe nuclei (DRN), periaqueductal grey area (PAG), hypothalamus (HT) and nucleus cuneiformis $(\mathrm{CN})(\mathrm{p}<0.0002$, voxel extent $=10)$. Using PPI analyses, we found enhanced connectivity of the sTN with the HT and the CN.

\section{Conclusions}

Our results are in line with previous animal and human imaging studies on brainstem processing of nociceptive stimuli. However, using the proposed high resolution

Department of Systems Neuroscience, University Medical Center HamburgEppendorf, Hamburg, Germany

(C) 2014 Schulte et al; licensee Springer. This is an Open Access article distributed under the terms of the Creative Commons Attribution License (http://creativecommons.org/licenses/by/2.0), which permits unrestricted use, distribution, and reproduction in any medium, provided the original work is properly cited. imaging technique, we achieved a more detailed insight into brainstem pain processing as compared to whole brain fMRI. High resolution brainstem fMRI of trigeminal nociceptive stimulation offers a unique opportunity to better understand headache pathophysiology.

No conflict of interest.

Published: 18 September 2014

doi:10.1186/1129-2377-15-S1-E33

Cite this article as: Schulte et al:: EHMTI-0154. Brainstem mechanisms of trigeminal nociception: an fMRI study at 3T. The Journal of Headache and Pain 2014 15(Suppl 1):E33.
Submit your manuscript to a SpringerOpen ${ }^{\bullet}$ journal and benefit from:

- Convenient online submission

- Rigorous peer review

- Immediate publication on acceptance

- Open access: articles freely available online

- High visibility within the field

Retaining the copyright to your article

Submit your next manuscript at $>$ springeropen.com 